Article

\title{
The Influence of the Porous Structure of Activated Coke for the Treatment of Gases from Coal Combustion on Its Mechanical Strength
}

\author{
Zhongjie Hu ${ }^{1,2}$, Heng Zhou ${ }^{1, *(D)}$, Weili Zhang ${ }^{1, *}$ and Shengli Wu ${ }^{1}$ \\ 1 School of Metallurgical and Ecological Engineering, University of Science and Technology Beijing, \\ Beijing 100083, China; huzhongjie@baosteel.com (Z.H.); wushengli@ustb.edu.cn (S.W.) \\ 2 Ironmaking Plant, Baoshan Iron and Steel Co., Ltd., Shanghai 201900, China \\ * Correspondence: zhouheng@ustb.edu.cn (H.Z.); zhangweili0408@163.com (W.Z.)
}

Received: 10 July 2020; Accepted: 22 July 2020; Published: 28 July 2020

check for updates

\begin{abstract}
This study investigated influences of the open/close states of pores and porosity distribution of activated coke on the mechanical strength of common activated coke for the purification of coal-fired flue gas by analyzing pore structure, abrasive resistance, and compression strengths of 9 types of desulfurization and denitration activated cokes. Research conclusions are conducive to disclosing the influences of porosity characteristics of activated coke for the purification of coal-fired flue gas on mechanical strength, decreasing the physical consumption of activated coke in the recycling of flue gas purification systems, and lowering the purification cost of coal-fired flue gas. According to research results, pores in the ranges of $0-2 \mathrm{~nm}$ and 2-500 $\mathrm{nm}$ of activated coke are further developed after recycling using the coal-fired flue gas purification system, and the average compression strength of activated coke is about $70 \%$ of the added fresh activated coke. However, the abrasive resistance of the recycled activated coke which has a smooth surface is higher than that of the fresh activated coke. Open pores are the main cause of reduced compression strength of activated coke. Open pores in the range of 2-500 $\mathrm{nm}$ can destroy the compression strength of activated coke the most. The open/close states of pores cause no significant impacts on the abrasive resistance of activated coke, but pores with diameters ranging from $0-2 \mathrm{~nm}$ can destroy the abrasive resistance of activated coke most significantly.
\end{abstract}

Keywords: activated coke; gas cleaning; porosity characteristics; compression strength; abrasive resistance; circular sorbent; pore diameter distribution

\section{Introduction}

Recently, the contradiction between environmental protection and pollutant emissions is increasingly prominent as a result of rapid industrial development in China. The "ultra-low emission" policy has proposed stricter requirements on pollutant emissions of energy-intensive industries (e.g., coal-fired power plants and iron and steel enterprises) in recent years. The $\mathrm{SO}_{2}$ and $\mathrm{NOx}$ limits for iron ore sintering flue gas are $35 \mathrm{mg} / \mathrm{m}^{3}$ and $50 \mathrm{mg} / \mathrm{m}^{3}$, respectively. As a sintering flue gas desulfurization and denitration technology that is expected to realize this "ultra-low emission", the activated coke flue gas treatment technology is extensively applied in China [1-4].

Activated coke is a circular sorbent and catalyst for the desulfurization and denitration of coal-fired flue gas and is the core of the activated coke flue gas purification system [5-12]. After denitration and desulfurization in the adsorption tower of the flue gas purification facilities, activated coke is transmitted to the regeneration tower for thermal regeneration, and the recycled activated coke is transmitted to the adsorption tower again for denitration and desulfurization. Then, activated coke recycling is finished in this adsorption-regeneration-adsorption circulation [13,14]. Nevertheless, 
the huge pressure from activated coke at the upper position of the adsorption tower and regeneration tower to the lower activated coke might cause the crushing of partially activated cokes in this process. Moreover, abrasiveness loss of activated coke is inevitable due to the friction behaviors between activated coke particles, between activated coke and device, and between activated coke and coal-fired flue gas. Consequently, some activated coke powder will be generated. To prevent deterioration of gas permeability of the activated coke layer by the activated coke powder, it is necessary to screen activated coke power smaller than $2 \mathrm{~mm}$ after thermal desorption, which will cause some physical loss of activated coke. Given the poorer compression strength and abrasive resistance of activated coke, more activated coke power will be formed in a single circulation, and the service life of the activated coke will be shorter. Activated coke consumption caused by crushing is an important cause of increasing costs for desulfurization and denitration of coal-fired flue gas. Therefore, activated coke used for high-quality desulfurization and denitration shall have not only good desulfurization and denitration performance, but also high compression strength and abrasive resistance.

The desulfurization and denitration efficiencies in the activated coke coal-fired flue gas purification system are satisfying, over $98 \%$ and $80 \%$, respectively. However, it incurs high activated coke consumption, resulting in a high cost for gas purification. Abundant studies on the influencing factors of desulfurization and denitration of coal-based activated coke have been reported, but there are few studies concerning the influencing factors of the mechanical strength of coal-based activated coke. As a result, it is still difficult to realize the production and selective purchase of high-strength activated coke on purpose. Generally speaking, a developed pore structure will lead to a loosing of the carbon skeleton of activated coke, thus deteriorating the mechanical strength of activated coke. However, which pore structural characteristic index influences the mechanical strength of activated coke still remains unknown. In addition, coal-based activated coke is widely used in coal-fired flue gas control due to its extensive source, high mechanical strength, and pore development $[15,16]$. Nevertheless, previous studies involve many types of activated cokes, thus failing to disclose influencing factors of the mechanical strength of coal-based activated coke [17]. In this study, pore structural characteristic indexes that influence the mechanical strength of common coal-based activated coke in China were investigated. Research conclusions can provide theoretical references for the production and selective purchase of activated cokes of high mechanical strength.

\section{Test Materials and Test Methods}

\subsection{Test Materials}

A total of 8 types of coal-based cylinder fresh activated coke samples (Fresh-1 Fresh-8) which are commonly used in coal-fired flue gas purification were applied as test materials in this study. In a large-sized steel mill in China, the activated coke used in the iron ore sintering flue gas purification facility is Cycle-x. This purification facility uses Fresh-1 as the adsorbent. Diameters of all activated coke samples are $9 \pm 0.25 \mathrm{~mm}$. Comparing the porous structures and mechanical strength indices of cycle-x and Fresh-1 can clarify the change law of the porous structure and mechanical strength of activated coke during recycling in the purification facility. Besides, the data of all activated coke are used to explore the relationship between the porous structure and the mechanical strength index.

\subsection{Characterization of Activated Coke Samples}

(1) The pore structure of activated coke. It can be seen from Figure 1 that there are many visible transverse pores in activated coke particles, and some pores are wrapped in activated coke, which are known as closed pores. Some pores extend from the inside of activated coke to surfaces, and some pores even run through the whole activated coke particles. Developed pores are conducive to the diffusion of the gas phase from inside to outside of activated coke and decrease internal diffusion resistance, thus increasing utilization inside of the activated coke particles and the pollutant purification rate of 
activated coke. However, the loose structure is easily constrained against the strength of activated coke when there is pressure, thus lowering its mechanical strength significantly.

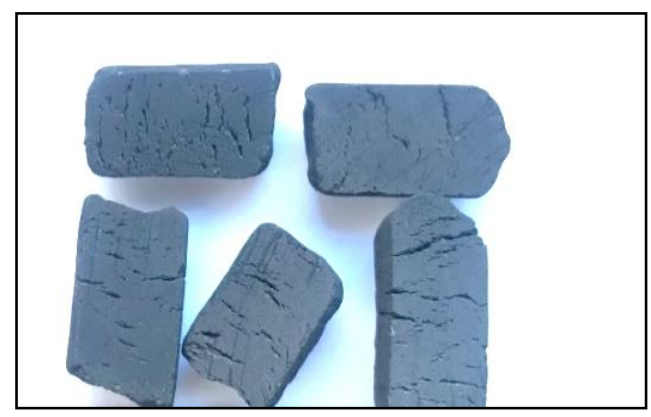

Figure 1. Longitudinal section images of Fresh-1.

Figure 2 was obtained using Quanta 250 FEG SEM (FEI, USA). It can be seen from Figure 2 that there are extensive developments of pore structures in activated coke, and pore distribution is obviously uneven. Most pores in activated coke are connected mutually, and pore diameter varies. Most small pores are branches of big ones, and the smaller pores are branches of small pores. Most pores have sharp ends. In addition to connected open pores, there are some independent closed pores embedded on the skeleton of the activated coke. Pores can be divided into full round pores and flat slit pores according to their shapes. The proportion of the volume sum of open and closed pores in the activated coke volume is the total porosity ratio, and the proportion of the volume of open pores in the activated coke volume is called the open porosity ratio.

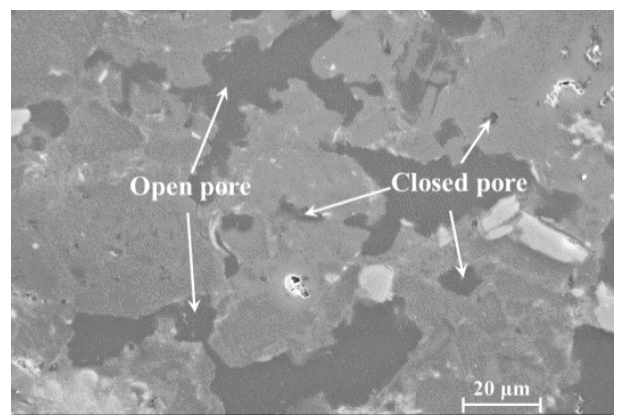

Figure 2. 2000 SEM images of Fresh-1.

(2) Test of the total porosity ratio and open porosity ratio of activated cokes: the true density of bulky activated coke (with closed pores) $\left(\rho_{B u l k y-T u r e}\right)$ and the true density of nano activated coke powder (closed pores can be ignored) ( $\left.\rho_{\text {Powder-Ture }}\right)$ were tested using a UPYC 1000 true density instrument. In this study, the nano activated coke powder was ground by the DECO high-energy planetary ball mill. The volume density of bulky activated coke $\left(\rho_{\text {Bulky-Bulk }}\right)$ was tested using the sealing wax and alcohol discharging method. The total porosity ratio and open porosity ratio of activated coke samples can be calculated using Equations (1) and (2) [18].

$$
\begin{aligned}
& R_{\text {Total }}=\frac{\rho_{\text {Powder-Ture }}-\rho_{\text {Bulky-Bulk }}}{\rho_{\text {powder }- \text { Ture }}} \\
& R_{\text {Open }}=\frac{\rho_{\text {Bulky-Ture }}-\rho_{\text {Bulky-Bulk }}}{\rho_{\text {Bulky-Ture }}}
\end{aligned}
$$

(3) Test of the pore diameter distribution in activated coke: pore diameter $(0-5 \mathrm{~nm})$ distribution and pore diameter $(>5 \mathrm{~nm}$ ) distribution in activated coke samples were gained using the Quadrasorb Station 1 nitrogen adsorption instrument (Quantachrome, USA) and the PoreMaster 60GT mercury injection 
apparatus (Quantachrome, USA). On this basis, the pore diameter distribution data of activated coke can be acquired. According to data analysis, porosity ratios in the ranges of 0-2 $\mathrm{nm}$ and 2-500 $\mathrm{nm}$ in coal-based activated coke were similar, while the porosity ratio (>500 nm) was higher. To explore the influences of pore diameter distribution on the mechanical strength of activated coke, pores in activated coke were divided into three ranges, namely, $0-2 \mathrm{~nm}, 2-500 \mathrm{~nm}$, and >500 nm. Correlations of porosity ratios in these three ranges and the mechanical strength of activated coke were discussed.

(4) Test of mechanical strength of activated coke: the mechanical strength of activated coke is characterized by compression strength and abrasive resistance. The compression strength and abrasive resistance of activated coke samples were tested using the crushing method and rotating inflation method (GB/T30202.3-2013). Results were applied in the follow-up discussion of mechanical strength and pore structure of activated coke.

\section{Results and Discussions}

\subsection{Influences of Porosity on Strength of Activated Coke in the Recycling Process}

The pores of activated coke are continuously distributed from a few tenths of a nanometer to a few tenths of a millimeter. As shown in Figure 3, the specific surface area presents a good linear relationship with 0-2 nm pore volume, and the correlation coefficient $R^{2}$ is up to 0.9960 . This result indicates the specific surface area of activated coke is mainly derived from pores with smaller pore diameters.

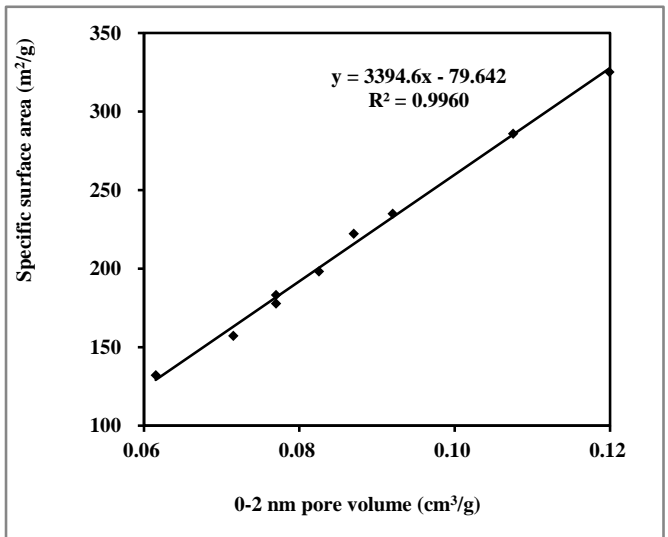

Figure 3. The correlation between $0-2 \mathrm{~nm}$ pore volume and specific surface area.

As can be seen from the porosity ratio in Table 1, most pores in activated coke are open. The closed pores only account for $5.64 \%$ of pores in fresh activated cokes, and they even account for $1.09 \%$ in recycled activated coke. Therefore, it can be speculated that some closed pores are opened during the recycling of activated cokes. The total porosity ratio of the recycled activated coke increases from $47.66 \%$ to $51.68 \%$. Therefore, the pore structure of activated coke will be further developed in the recycling process. This is mainly because the sulfuric acid which is a product of desulfurization reacts with the fixed carbon in the activated coke to generate $\mathrm{CO}_{2}$ during the thermal desorption, thus further activating the activated coke. The skeleton of activated coke is corroded and new pores are formed [17,19-21]. In addition, some closed pores in the recycled activated coke are opened, which is one reason for the further increase in pore structure in activated coke.

According to pore diameter distribution data, porosity ratios of Cycly-x in ranges of 0-2 nm, 2-500 nm, and >500 $\mathrm{nm}$ are higher than those of Fresh-1. In the particle, the porosity ratios of Cycly-x in ranges of 0-2 $\mathrm{nm}$ and 2-500 $\mathrm{nm}$ are significantly higher than those of Fresh-1. This might be because the desulfurization reaction is in the micropores and desulfurization products are mainly stored in small pores. Hence, pore expansion mainly occurs in the small size range. Based on a comparison of mechanical strength indexes of Cycle- $x$ and Fresh-1, the average compression strength of Cycle- $x$ is about $70 \%$ of that of Fresh-1 due to the further development of porosity in Cycle-x. However, Cycle-x 
shows stronger abrasive resistance than Fresh-1 since its surface becomes smooth and more difficult to make abrasive after recycling.

Table 1. Comparison of porosity characteristics and mechanical strengths of activated coke before and after recycling.

\begin{tabular}{|c|c|c|c|c|c|c|c|c|}
\hline \multirow[b]{2}{*}{$\begin{array}{c}\text { Sample } \\
\text { No. }\end{array}$} & \multicolumn{2}{|c|}{ Open/Close State of Pores } & \multicolumn{3}{|c|}{ Pore Diameter Distribution } & \multicolumn{2}{|c|}{ Mechanical Properties } & \multirow{2}{*}{$\begin{array}{c}\text { Specific } \\
\text { Surface Area } \\
\left(\mathrm{m}^{2}\right)\end{array}$} \\
\hline & $\begin{array}{c}\text { Total Porosity } \\
\text { Ratio } \\
\text { (\%) }\end{array}$ & $\begin{array}{c}\text { Open Porosity } \\
\text { Ratio } \\
(\%)\end{array}$ & $\begin{array}{l}0-2 \mathrm{~nm} \\
\left(\mathrm{~cm}^{3} / \mathrm{g}\right)\end{array}$ & $\begin{array}{c}2-500 \mathrm{~nm} \\
\left(\mathrm{~cm}^{3} / \mathrm{g}\right)\end{array}$ & $\begin{array}{c}>500 \mathrm{~nm} \\
\left(\mathrm{~cm}^{3} / \mathrm{g}\right)\end{array}$ & $\begin{array}{l}\text { Compression } \\
\text { Strength } \\
\text { (N) }\end{array}$ & $\begin{array}{c}\text { Abrasive } \\
\text { Resistance } \\
(\%)\end{array}$ & \\
\hline Fresh-1 & 47.66 & 42.02 & 0.0825 & 0.0814 & 0.1539 & 499 & 97.18 & 198.3 \\
\hline Cycly-x & 51.68 & 50.49 & 0.1199 & 0.1225 & 0.1623 & 340 & 98.88 & 325.2 \\
\hline
\end{tabular}

\subsection{Effects of Pore Structure on Compression Strength}

\subsubsection{Effects of Open/Close State of Pores on Compression Strength}

To discuss the influences of the open/close states of pores on the compression strength of activated coke, correlations of the total porosity ratio and open porosity ratio with the compression strength were fitted in this section. Results are shown in Figures 4 and 5 (where the square mark is the recycled activated coke). In Figure 4, compression strength is negatively correlated with the total porosity ratio, but the correlation coefficient $\left(R^{2}\right)$ in the linear fitting results is only 0.8493 . However, the $R^{2}$ in the independent fitting of fresh activated coke reaches as high as 0.9798 . To sum up, there is a good linear relationship between the compression strength of fresh activated coke and its total porosity ratio, but this linear relationship is inapplicable to recycled activated coke. Hence, it is inferred that there are some differences in porosity characteristics between fresh and recycled activated coke, so that the total porosity ratio is difficult to use to characterize the compression strength of all activated cokes comprehensively.

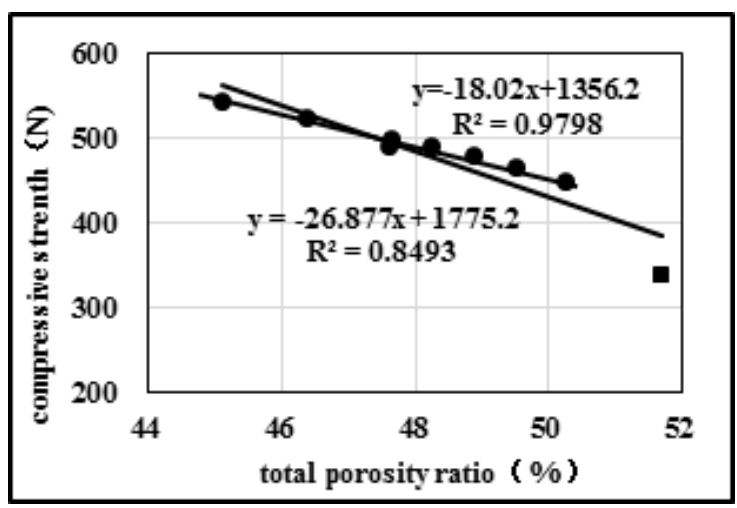

Figure 4. Correlation between the total porosity ratio and compression strength.

It can be seen from Figure 5 that there is a good negative correlation between the open porosity of activated coke and compression strength, with the $\mathrm{R}^{2}$ reaching 0.9690 . Moreover, the fit linear equation is applicable to both fresh and recycled activated cokes. According to fitting results in Figure 4, open pores and closed pores cause different damages to the compression strength of activated coke. Instead of total pores including closed pores, open pores are the main pore type that decreases the compression strength of activated coke. The closed porosity ratio in recycled activated coke is decreased. As a result, the relationship between the compression strength and the total porosity ratio of the recycled activated coke is weaker than that of fresh activated coke.

Activated coke is a kind of brittle material with many defects (e.g., cracks and pores) in its base. According to the brittle fracture mechanism, a brittle fracture is mainly caused by a defect extension upon stress concentration nearby under the effect of external forces [21]. The sharp pore end of 
inactivate coke provides a good condition for stress concentration. For open pores, the sharp end will generate a strong stress concentration under external forces. Under this circumstance, the tensile stress at the pore end is several times that of the average tensile stress on the stress surface of activated coke, which results in the breakage of activated cokes. However, some closed pores have round edges with relatively weak stress concentrations. Slit closed pores generally have two symmetric sharp ends. When the activated coke receives an external force, the two sharp ends of closed pores share it. Therefore, the stress on closed pore ends is significantly lower than the stress at the ends of open pore cracks. Consequently, closed pores generally are difficult and weak positions for the compression strength of activated coke.

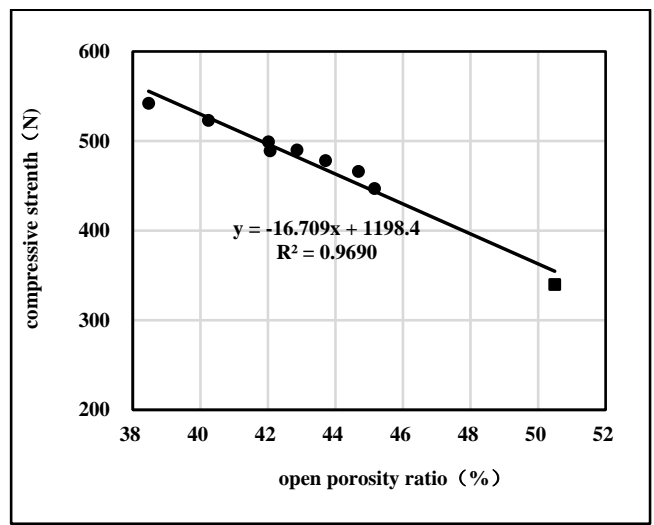

Figure 5. Correlation between the open porosity ratio and compression strength.

\subsubsection{Effects of Pore Diameter Distribution on Compression Strength}

To analyze influences of pore distribution in activated coke on the compression strength, correlations of compression strength with pore volume within ranges of $0-2 \mathrm{~nm}, 2-500 \mathrm{~nm}$, and $>500 \mathrm{~nm}$ were fitted in this section. The results are shown in Figures 6-8. Although pore volumes in the ranges of $0-2 \mathrm{~nm}$ and 2-500 $\mathrm{nm}$ are close, the correlation between pore volume in the range of 0-2 $\mathrm{nm}$ and compression strength is stronger, and the slope of the fit straight is higher. Within the range of $0-2 \mathrm{~nm}$, compression strength declines by $33.951 \mathrm{~N}$ for every growth of pore volume by $0.01 \mathrm{~cm}^{3} / \mathrm{g}$. This reflects that 2-500 nm pores can destroy the compression strength of activated coke more significantly. The pore volumes of $>500 \mathrm{~nm}$ pores are significantly higher than those of $0-2 \mathrm{~nm}$ and $2-500 \mathrm{~nm}$ pores, but the correlation with the compression strength is weaker. Hence, $>500 \mathrm{~nm}$ pores decrease the compression strength of less than $0-2 \mathrm{~nm}$ and 2-500nm pores. To sum up, 2-500 $\mathrm{nm}$ pores influence compression strength the most significantly.

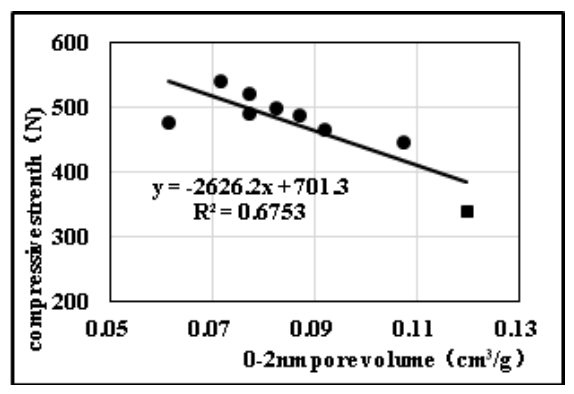

Figure 6. The correlation between $0-2 \mathrm{~nm}$ pore volume and compression strength.

According to the crushing mechanism analysis of activated coke, stress concentration plays an important role in the crushing process of activated coke. If there is stronger stress concentration in the pores and there are more pores that can generate stress concentration, the compression strength 
of activated coke is smaller. The stress concentration is not only related to defect shape but also is positively correlated with the pore diameter and length-width ratio of pores [22]. For the single pore, bigger pores have higher stress concentration coefficients. Although a $>500 \mathrm{~nm}$ pore can harm compression strength greatly, the general influence of $>500 \mathrm{~nm}$ pores on compression strength is small due to their small quantity. Given the same pore volume, the number of $0-2 \mathrm{~nm}$ pores is tens of thousands of times that of 2-500 nm pores. However, micropores are generally superficial with small length-width ratios. Therefore, micropores have relatively small stress concentration coefficients, thus causing small influences on the compression strength.

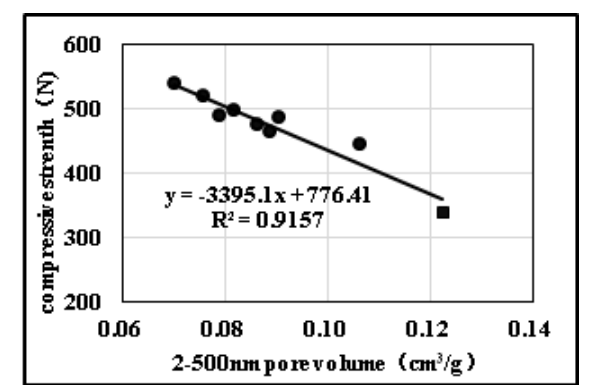

Figure 7. The correlation between $2-500 \mathrm{~nm}$ pore volume and compression strength.

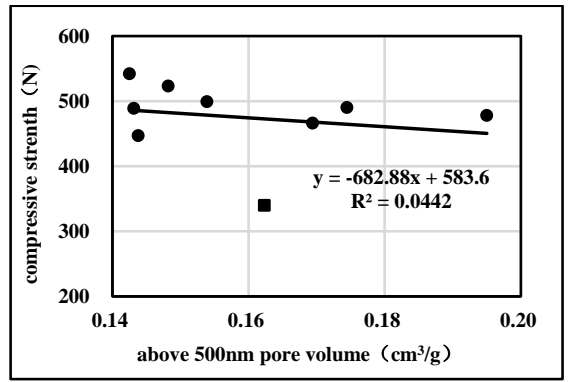

Figure 8. The correlation between $>500 \mathrm{~nm}$ pore volume and compression strength.

\subsection{Effects of Pore Structure on Abrasive Resistance}

\subsubsection{Effects of Open/Close State of Pores on Abrasive Resistance}

To investigate the influences of the porosity ratio on the abrasive resistance of activated coke, correlations of abrasive resistance with the total porosity ratio and open porosity ratio of activated coke were fitted. The results are shown in Figures 9 and 10. Except for Cycly-x, all activated coke samples show certain negative correlations of abrasive resistance with the total porosity ratio and open porosity ratio. However, $R^{2}$ only has values 0.4154 and 0.3935 . The weak correlations between porosity ratios and abrasive resistance prove that not all pores within the pore diameter ranges can influence abrasive resistance significantly. In addition to the porosity ratio, abrasive resistance might be related to surface roughness, ash content, and other factors. The $\mathrm{R}^{2}$ of two correlations presents a small difference, indicating the insignificant impacts of the open/close state of pores on the abrasive resistance of activated cokes. This implies that porosity ratio data alone is difficult to use to determine the abrasive resistance performances of activated coke. Moreover, the small difference between the $\mathrm{R}^{2}$ of two correlations reflects the small relative impacts of the open/close states of pores on the abrasive resistance of activated coke.

Abrasion of activated coke occurs when pressure on activated coke particles is smaller than the crushing strength. Hence, the abrasion of activated coke is attributed to low-stress scratching abrasive wear. The abreaction of activated coke is at the interface of particles, and the shearing stress generated by the relative movement of particles may lead to layer-by-layer peeling of the particle surface. For this reason, only pores near activated coke's surface can influence abrasion significantly. 
After layer-by-layer peeling, the closed pores in activated coke will be finally exposed to the activated coke's surface and change to open ones, and thereby influencing the abrasive resistance of the activated coke. Hence, the early open/close state of pores in activated coke particles influences the abrasive resistance slightly.

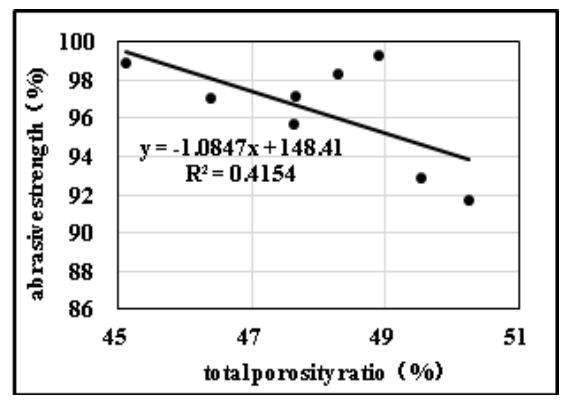

Figure 9. The correlation between the total porosity ratio and abrasive resistance.

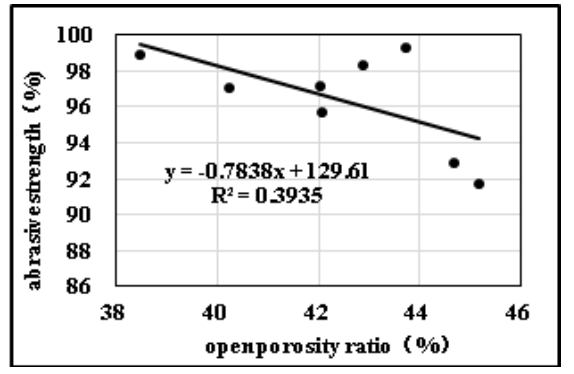

Figure 10. The correlation between the open porosity ratio and abrasive resistance.

\subsubsection{Influences of Pore Diameter Distribution on Abrasive Resistance}

Correlations between $0-2 \mathrm{~nm}, 2-500 \mathrm{~nm}$, and $>500 \mathrm{~nm}$ pores pore volumes in 8 types of activated coke samples (except cycle-x) and abrasive resistance are shown in Figures 11-13. According to fitting results, the abrasive resistance of activated coke is closer to the $0-2 \mathrm{~nm}$ pore volume than the $2-500 \mathrm{~nm}$ pore volume. The abrasive resistance of activated coke decreases by $1.9008 \%$ when the $0-2 \mathrm{~nm}$ pore volume is increased by $0.01 \mathrm{~cm}^{3} / \mathrm{g}$. Besides, the abrasive resistance of activated coke shows no evident correlation with $>500 \mathrm{~nm}$ pore volume. Therefore, small pores take the dominant role in destroying the abrasive resistance. Given a fixed pore volume, abrasive resistance declines more significantly if there are more small pores. Different from compression strength, abrasive resistance is the ability of the activated coke surface to resist shearing stress failures. The abrasive resistance of activated coke is higher if the binding force of particles on the surface is stronger. The microconvex model of abrasive resistance of materials reflects that there is a dense distribution of microconvexes with different heights on the material's surface. When external particles and microconvexes contact and make relative movement, the microconvexes will become a stress mass point on the material's surface. The stress mass point will break via cutting of the experimental particles, thus forming abrasive dust [23]. If the pore volume is fixed and the pore diameter is smaller, there are more pores and the stress mass points are smaller. As a result, a smaller pore diameter can destroy the abrasive resistance of activated coke more efficiently under the same pore volume. 


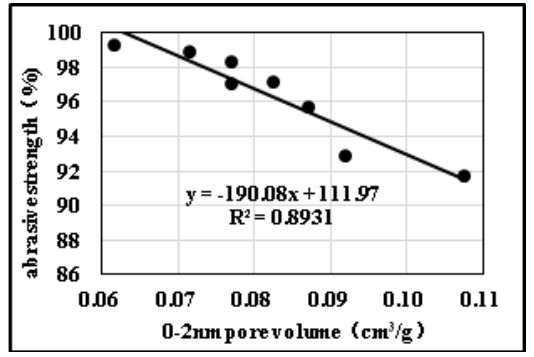

Figure 11. The correlation between $0-2 \mathrm{~nm}$ pore volume and abrasive resistance.

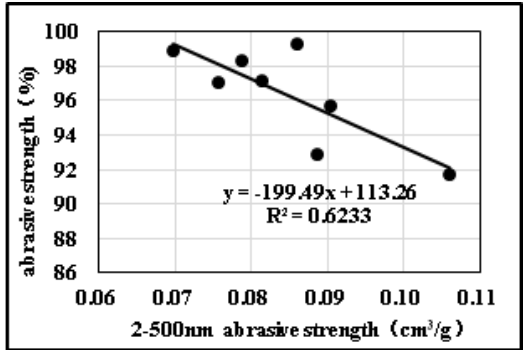

Figure 12. The correlation between $2-500 \mathrm{~nm}$ pore volume and abrasive resistance.

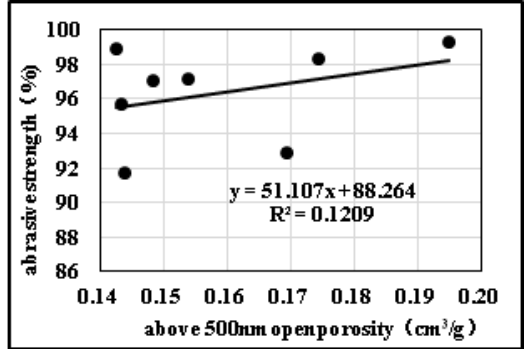

Figure 13. The correlation between $>500 \mathrm{~nm}$ pore volume and abrasive resistance.

\section{Conclusions}

(1) The pore structure in recycled activated coke is further developed, resulting in a reduction of compression strength. The average compression strength of activated coke in coal-fired flue gas purification gas is about 70\% of that of fresh activated coke. Activated cokes that are recycled from the fluid bed purification system have smooth surfaces which are difficult to wear further. Therefore, the abrasive resistance of recycled activated coke is higher compared to that of fresh activated coke.

(2) The compression strength of activated coke shows a good positive correlation with the open porosity ratio. The $2-500 \mathrm{~nm}$ open pores are the primary influencing factor of the compression strength of activated coke. After the pore structure is further developed during the recycling process, this correlation is also applicable to recycled activated coke.

(3) There is a certain positive correlation between the abrasive resistance and the total porosity ratio of activated coke. The open/close state of the pores cannot significantly reduce the abrasive resistance of activated cokes. Given the same pore volume, small pores can most efficiently destroy the abrasive resistance of activated coke. The linear fitting relationship between the abrasive resistance and pore diameter of recycled activated coke is not applicable to fresh activated coke.

Author Contributions: Conceptualization, Z.H., S.W. and W.Z.; Data curation, S.W.; Formal analysis, W.Z.; Funding acquisition, S.W.; Investigation, W.Z.; Methodology, W.Z.; Project administration, S.W.; Resources, S.W.; Software, H.Z.; Supervision, S.W.; Validation, W.Z., H.Z.; Visualization, W.Z.; Writing-original draft, W.Z.; Writing-review \& editing, H.Z. All authors have read and agreed to the published version of the manuscript.

Funding: This research was funded by National Natural Science Foundation of China grant number 51904023. The APC was funded by it, too. 
Acknowledgments: The authors would like to thank the financial support of Fundamental Research Funds for the Central Universities (Grant Number FRF-IC-18-010).

Conflicts of Interest: The authors declare no competing financial interest.

\section{References}

1. Ruan, Z.Y. Desulfurization and denitration of sintering flue gas based on ammonia and activated carbon process. Iron Steel 2017, 52, 91-97.

2. Liu, Z.G.; Cang, D.Q.; Dan, Z.G. Experimental study on the factors of affecting sintering flue gas desulphurization of activated carbon. Energy Metal. Ind. 2008, 27, 56-63.

3. Ogriseck, S.; Vanegas, G.P.G. Experiment investigation of ammonia adsorption and nitric oxide reduction on activated coke. Chem. Eng. J. 2010, 160, 641-650. [CrossRef]

4. Shao, J.G.; Zhang, J.J.; Zhang, X.; Feng, Y.; Zhang, H.; Zhang, S.; Chen, H. Enhance SO2 adsorption performance of biochar modified by CO2 activation and amine impregnation. Fuel 2018, 224, 138-146. [CrossRef]

5. Sadraei, R.; Paganini, M.C.; Calza, P.; Magnacca, G. As easy synthesis for preparing bio-based hybrid adsorbent useful for fast adsorption of polar pollutants. Nanomaterials 2019, 9, 731. [CrossRef]

6. Figueiredo, J.L.; Pereira, M.F.R.; Freitas, M.M.A. Modification of the surface chemistry of activated carbons. Carbon 1999, 37, 1379-1389. [CrossRef]

7. Jüntgen, H.; Richter, E.; Knoblauch, K. Catalytic NOx reduction by ammonia on carbon catalysts. Chem. Eng. Sci. 1988, 43, 419-428. [CrossRef]

8. Knoblauch, K.; Richter, E.; Jüntgen, H. Application of active coke in process of SO2-and NOx-removal from flue gases. Fuel 1981, 60, 832-838. [CrossRef]

9. Richter, E.; Knoblauch, K.; Jüntgen, H. Mechanisms and kinetics of SO2 adsorption and NOx reduction on active coke. Gas Sep. Purif. 1987, 1, 35-43. [CrossRef]

10. Olson, D.G.; Tsuji, K.; Shiraishi, I. The reduction of gas phase air toxics from combustion and incineration sources using the MET-Mitsui-BF activated coke process. Fuel Process. Technol. 2000, 65, 393-405. [CrossRef]

11. Li, Y.; Guo, Y.; Zhu, T.; Ding, S. Adsorption and desorption of SO2, NO and chlorobenzene on activated carbon. J. Environ. Sci. 2016, 43, 128-135. [CrossRef]

12. Wang, W.W.; Xu, S.P.; Wang, K.C.; Liang, J.; Zhang, W. De-intercalation of the intercalated potassium in the preparation of activated carbons by KOH activation. Fuel Process. Technol. 2019, 189, 74-79. [CrossRef]

13. Mochida, I.; Korai, Y.; Shirahama, M. Removal of Sox and NOx over activated carbon fibers. Carbon 2000, 38 , 227-239. [CrossRef]

14. Jastrzab, K. Changes of activated coke properties in cyclic adsorption treatment of flue gases. Fuel Process. Technol. 2012, 104, 371-377. [CrossRef]

15. Wu, H.; Wall, T.; Liu, G. Ash liberation from included minerals during combustion of pulverized coal: The relationship with char structure and burnout. Energy Fuels 1999, 13, 1197-1202. [CrossRef]

16. Wu, H.; Bryant, G.; Wall, T. The effect of pressure on ash formation during pulverized coal combustion. Energy Fuels 2000, 14, 745-750. [CrossRef]

17. Wang, P.; Xie, W.; Li, L.; Xiong, Y. Evolution of pore structure and surface characteristics of activated coke during circulations of desulfurization and regeneration. J. China Coal Soc. 2016, 41, 751-759. (In Chinese)

18. GB/T9966.3-2001, Test Methods for Natural Facing Stone. Part 3: Test Methods for Bulk Density, True Density, True Porosity, and Absorption Rate. Available online: http://www.bzxz.net/bzxz/39564.html (accessed on 20 July 2020).

19. Komatsubara, Y.; Shiraishi, I.; Yano, M. Preparation of active coke for the simultaneous removal of SOx and NOx in the flue gas. J. Fuel Soc. Jpn. 1985, 64, 255-263. [CrossRef]

20. Li, Y.; Li, X.; Chang, L.; Wu, D.; Fang, Z.; Shi, Y. Understandings on the scattering property of the mechanical strength data of solid catalysts: A statistical analysis of iron-based high-temperature water-gas shift catalysts. Catal. Today 1999, 51, 73-84. [CrossRef]

21. Xing, X. A statistical theory of brittle fracture. Acta Phys. Sin. 1980, 29, 718-731. 
22. Chen, L.; Fang, K.; Fu, S. Effects of Pore and Crack on Stress Concentration in Welded Joint. Hot Work. Technol. 2014, 43, 213-215.

23. Tang, Z.; Huang, R.; Jiao, Y.; Tan, F.; Zhu, X. Theoretical closure model for rock joints considering interaction of deformations of substrate deformation and asperity. Chin. J. Geotech. Eng. 2017, 39, 1800-1806.

(C) 2020 by the authors. Licensee MDPI, Basel, Switzerland. This article is an open access article distributed under the terms and conditions of the Creative Commons Attribution (CC BY) license (http://creativecommons.org/licenses/by/4.0/). 